\title{
Optical splitter design for telecommunication access networks with triple-play services
}

\author{
Rajdi Agalliu*, Catalina Burtscher*,**, \\ Michal Lucki*, Dana Seyringer ${ }^{* *}$
}

\begin{abstract}
In this paper, we present various designs of optical splitters for access networks, such as GPON and XG-PON by ITU-T with triple-play services (ie data, voice and video). The presented designs exhibit a step forward, compared to the solutions recommended by the ITU, in terms of performance in transmission systems using WDM. The quality of performance is represented by the bit error rate and the Q-factor. Besides the standard splitter design, we propose a new length-optimized splitter design with a smaller waveguide core, providing some reduction of non-uniformity of the power split between the output waveguides. The achieved splitting parameters are incorporated in the simulations of passive optical networks. For this purpose, the OptSim tool employing Time Domain Split Step method was used.
\end{abstract}

K e yw ords: optical splitter design, optical fiber communication, optical fiber networks, telecommunication network reliability, WDM networks

\section{Introduction}

Optical access networks (OAN) mostly use a tree topology to distribute services from the optical line terminal (OLT) on the provider's side to subscribers in an optical network unit (ONU). While designing such networks, one has to consider different aspects like optical linear and nonlinear effects [1], optical attenuation and amplification [2], possible wavelength routing [3], or ageing of network elements [4], among others.

Optical splitters that can split one signal into $N$ output signals without performing any other adjustments, can handle the signal distribution from OLT to ONUs. They are the key components in passive optical networks $(\mathrm{PON})$, as they are beneficial to reduce the overall network cost implementation. They are easy for maintenance and troubleshooting, too.

A splitter can be designed as a cascade of one-bytwo waveguide branches, known as Y-branch splitter. The main benefit of this solution is its polarization and wavelength independency, which enables signal distribution in the entire operating wavelength range, for which optical fibres are transparent. On the other hand, fabrication of the branching points is demanding and this process generally faces with several issues, as for example asymmetric splitting ratio (known as non-uniformity). Additionally, to keep the losses as low as possible the curvature of the Y-branches has to be very low, leading to a rather long chip size. The core size of the waveguides is a key parameter in the splitter's design. The commonly used size is $6 \mu \mathrm{m} \times 6 \mu \mathrm{m}$ to match the single mode fiber (SMF) diameters in order to minimize the coupling los. It was shown that the Y-branch splitters with a smaller waveguide core size have much lower non-uniformity of the split power enhancing the system performance of the network [5].

The multiplexing techniques used with the splitters are required to efficiently utilize the available bandwidth and transmission media. One of the main multiplexing techniques used in PONs is the time division multiplexing $(\mathrm{TDM})$, in which a certain time-slot is assigned to each of the ONUs. The recommendations, in which the most of the OANs are based on, are: GPON [6] and EPON [7]. In this paper, we focus on GPON, since it offers higher bandwidth than EPON. In the simulations, we consider its 10 Gbit option, as recommended by ITU-T: XG-PON [8]. The simulations were performed in OptSim environment, version 5.2, by RSoft Design [9].

\section{State of art}

Optical splitters are used in optical distribution networks (ODN) either in pure TDM PONs, or for wavelength division multiplexing (WDM) PONs [10], but also in hybrid broadband access networks [11], as well as they are recommended for the future ultra-dense WDM PONs $[12,13]$. The authors in [14] analysed the impact of different types of splitter structures in PONs on resource sharing and power consumption and they showed that the combination of cascaded splitters with the extended reach is the most beneficial. The authors in [15] proposed a mathematical model for PON planning, where splitter allocation, attenuation and ratio are considered. Optical splitters can enhance the PON design, as shown

* Czech Technical University in Prague, Faculty of Electrical Engineering, Department of Telecommunications Engineering, Technicka 2, 16627 Prague 6, Czech Republic, ** Vorarlberg University of Applied Sciences, Research Centre for Microtechnology, Hochschulstr. 1, 6850 Dornbirn, Austria, agallraj@fel.cvut.cz 
in $[16,17]$. For the design of splitters, many factors have to be considered. For example, the branching angle in $\mathrm{Y}$ branch optical splitters can directly affect the power loss. Authors in [18] showed that the power loss is higher for wide angle. The key parameter of splitters is the splitting ratio. There is an interest in finding how to increase the splitting ratio, because in this way it is possible to connect more users through the same transmission media and thus potential reduction of the overall network implementation and maintenance costs is possible. Authors in [19] described how to design novel splitters, with very low insertion loss and small channel non-uniformity over the range from $1530 \mathrm{~nm}$ to $1570 \mathrm{~nm}$. Asymmetric splitters can be used mainly for balancing the attenuation of ODNs. Well-optimized optical splitters are crucial for the long-reach, dense grid, and high split ratio PONs [20]. Three-branch splitter structures can improve the uniformity. Authors in [21] model a novel 1x24 splitter with a three-branch structure and 21 Y-branch elements, which has low insertion loss and good uniformity.

In this paper, we present the standard 164 Y-branch splitter with $6 \mu \mathrm{m} \times 6 \mu \mathrm{m}$ waveguide core size and lengthoptimized 164 splitter with $5.5 \mu \mathrm{m} \times 5.5 \mu \mathrm{m}$ waveguide core size. The network design is based on GPON [6] and XG-PON [8]. We employed ITU-T recommendation [8] for the wavelength ranges, respecting those shown in Fig. 1 .

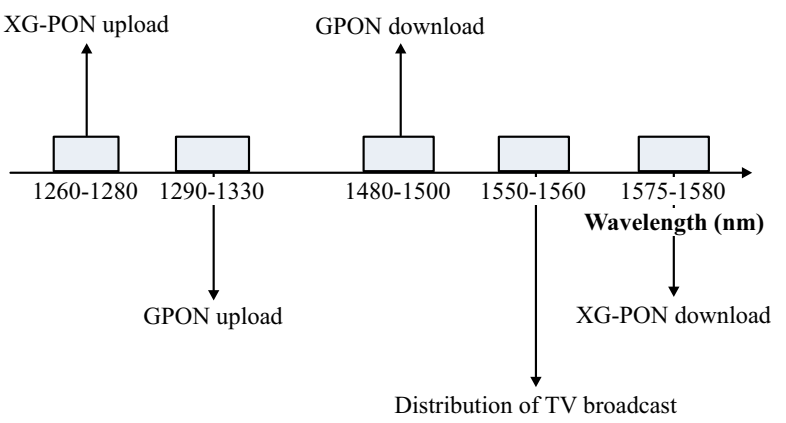

Fig. 1. Wavelength ranges for GPON/XG-PON and video components

Allocation of the wavelengths recommended by ITU-T is selected to avoid cross-talks between GPON and XGPON signals. A $10 \mathrm{~nm}$ wavelength window is allocated for the distribution of the video, as shown in Fig. 1.

\section{Optical splitter design}

The Y-branch splitters were designed and optimized in OptiBPM photonic tool from Optiwave. The input design parameters are shown in Tab. 1.

Table 1. Design parameters for $164 \mathrm{Y}$-branch splitters

\begin{tabular}{lc}
\hline Refractive index of the core, $n_{c}$ & 1.456 \\
Refractive index of the cladding, $n_{c l}$ & 1.445 \\
Refractive index contrast, $\Delta n$ & $0.75 \%$ \\
Operating wavelength, $\lambda$ & $1550 \mathrm{~nm}$ \\
\hline
\end{tabular}

The structural parameters of the proposed splitter are shown in Fig. 2. We used the s-bend-arc shapes of Y-branches, since they enable the lowest losses [22]. 63 branches that are required for 64 linear outputs are distributed into six branch layers. The port pitch of the output branches, where the fibres are connected, is set to $127 \mu \mathrm{m}$, ie parameter $W(1 s t)$. To keep propagation losses as small as possible we set the length of the 1st branch layer $L(1 s t)$ to $5000 \mu \mathrm{m}$.

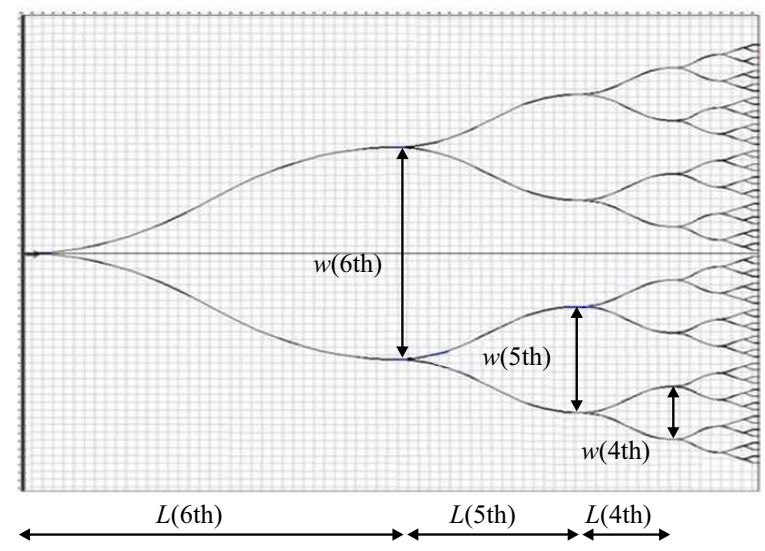

Fig. 2. Standard $1 \times 64$ Y-branch splitter structure designed using OptiBPM layout designer sub-program. Length $318 \mathrm{~mm}$, width $63 \times 127=8001 \mu \mathrm{m}$

The remaining lengths and widths of branch layers are given in Tab. 2. These two parameters are doubled from one layer to another to keep constant bending shape. As a result, the total length of the standard 164 splitter reached $318000 \mu \mathrm{m}$ and its width is $8001 \mu \mathrm{m}$, considering that the input and output port lengths are $1000 \mu \mathrm{m}$.

Figure 3 shows the simulated results. The field distribution at the output waveguides is shown in Fig. 3(a). As presented the background isolation, $B X$ is better than $-42 \mathrm{~dB}$. Detailed view of the field displaying the nonuniformity (difference between the highest and the lowest peak), $I L u=2.67 \mathrm{~dB}$ and the insertion loss (the lowest peak in the distribution), $I L=-19.89 \mathrm{~dB}$ can be seen in Fig. 3(b).

The splitter length can be optimized, as explained in [23]. The individual widths and lengths of branch layers of this length-optimized splitter are given in Tab. 3. As can be seen, the widths remain the same as in the standard Y-branch splitter.

The layout of the length-optimized $1 \times 64$ Y-branch optical splitter is shown in Fig. 4. As can be seen the overall splitter length has been reduced from $318000 \mu \mathrm{m}$ to $120000 \mu \mathrm{m}$.

Simulation results showed that a factor, which affects the optical properties of the splitter, is the presence of the first mode in the used waveguide structure. The first 

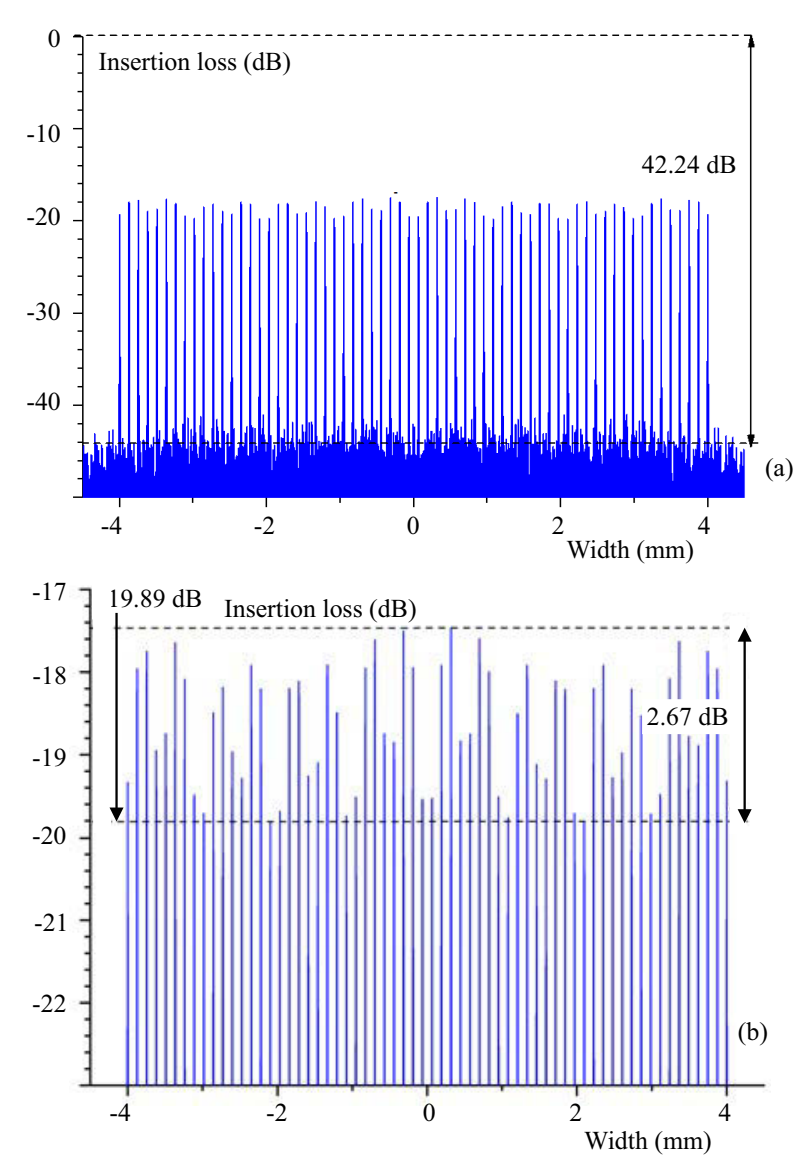

Fig. 3. $1 \times 64$ Y-branch standard splitter, core $6 \times 6 \mu \mathrm{m}^{2}:(\mathrm{a})-$ Field distribution at the output of the modeled splitter and the background isolation, $B X=-42.24 \mathrm{~dB}$; (b) - Detailed view of the field displaying the non-uniformity, $I L u=2.67 \mathrm{~dB}$ and the insertion loss, $I L=-19.89 \mathrm{~dB}$

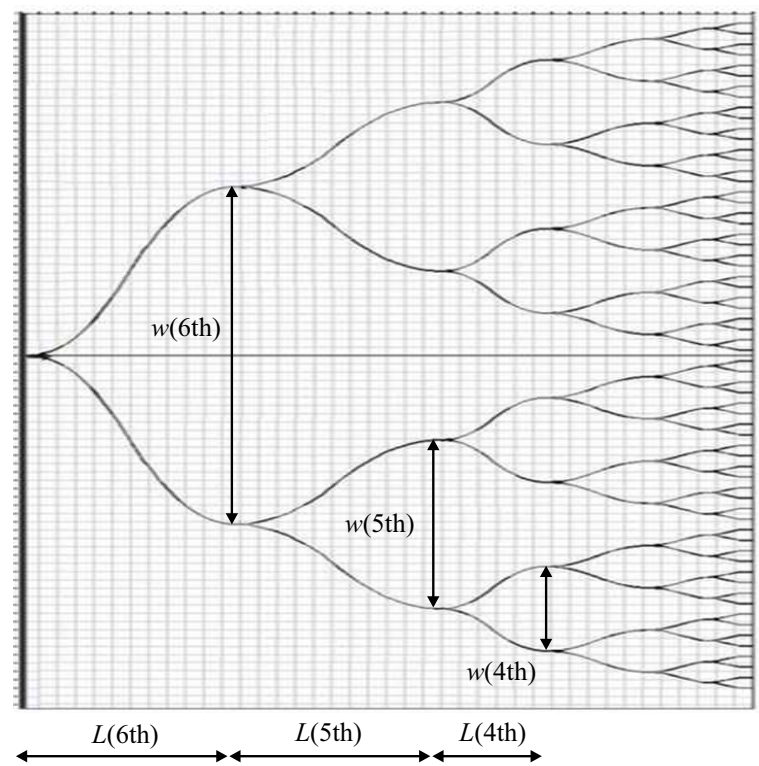

Fig. 4. Layout of the length-optimized $1 \times 64$ Y-branch splitter (low-loss length optimized) Length $120 \mathrm{~mm}$, width $63 \times 127=$ $8001 \mu \mathrm{m}$

mode (beside the zero one) can be suppressed by reducing the waveguide core size from $6 \mu \mathrm{m} \times 6 \mu \mathrm{m}$ to $5.5 \mu \mathrm{m} \times 5.5 \mu \mathrm{m}$ and keeping constant size of the Y-branch splitter structures [5]. This reduction leads to strong improvement of the optical properties of the splitter and on the other hand offers the possibility to optimize the length of the splitter. Figure 5 shows the simulation results of such $1 \times 64$ length-optimized splitter presented in Fig. 4 . As can be observed even the length of the splitter was reduced to the nearly one third of the original length, the non-uniformity, $I L u=1.98 \mathrm{~dB}$ was suppressed by about $0.7 \mathrm{~dB}$. Insertion loss $I L=-19.93 \mathrm{~dB}$ together with background crosstalk $B X$ remained very similar.

Table 2. Widths and lengths of branch layers in standard 164 splitter

\begin{tabular}{lcc}
\hline & $W\left(1^{\text {st }}\right)$ & $127 \mu \mathrm{m}$ \\
& $W\left(2^{\text {nd }}\right)$ & $254 \mu \mathrm{m}$ \\
Widths of & $W\left(3^{\text {rd }}\right)$ & $508 \mu \mathrm{m}$ \\
branch layers & $W\left(4^{\text {th }}\right)$ & $1016 \mu \mathrm{m}$ \\
& $W\left(5^{\text {th }}\right)$ & $2032 \mu \mathrm{m}$ \\
& $W\left(6^{\text {th }}\right)$ & $4064 \mu \mathrm{m}$ \\
\hline & $L\left(1^{\text {st }}\right)$ & $5000 \mu \mathrm{m}$ \\
Lengths of & $L\left(2^{\text {nd }}\right)$ & $10000 \mu \mathrm{m}$ \\
branch layers & $L\left(3^{\text {rd }}\right)$ & $20000 \mu \mathrm{m}$ \\
& $L\left(4^{\text {th }}\right)$ & $40000 \mu \mathrm{m}$ \\
& $L\left(5^{\text {th }}\right)$ & $80000 \mu \mathrm{m}$ \\
& $L\left(6^{\text {th }}\right)$ & $160000 \mu \mathrm{m}$ \\
\hline
\end{tabular}

Table 3. Widths and lengths of branch layers in length optimized $1 \times 64$ Y-branch splitter

\begin{tabular}{lcc}
\hline & $W\left(1^{\text {st }}\right)$ & $127 \mu \mathrm{m}$ \\
& $W\left(2^{\text {nd }}\right)$ & $254 \mu \mathrm{m}$ \\
Widths of & $W\left(3^{\text {rd }}\right)$ & $508 \mu \mathrm{m}$ \\
branch layers & $W\left(4^{\text {th }}\right)$ & $1016 \mu \mathrm{m}$ \\
& $W\left(5^{\text {th }}\right)$ & $2032 \mu \mathrm{m}$ \\
& $W\left(6^{\text {th }}\right)$ & $4064 \mu \mathrm{m}$ \\
\hline & $L\left(1^{\text {st }}\right)$ & $5000 \mu \mathrm{m}$ \\
Lengths of & $L\left(2^{\text {nd }}\right)$ & $10000 \mu \mathrm{m}$ \\
branch layers & $L\left(3^{\text {rd }}\right)$ & $17000 \mu \mathrm{m}$ \\
& $L\left(4^{\text {th }}\right)$ & $17000 \mu \mathrm{m}$ \\
& $L\left(5^{\text {th }}\right)$ & $34000 \mu \mathrm{m}$ \\
& $L\left(6^{\text {th }}\right)$ & $34000 \mu \mathrm{m}$ \\
\hline
\end{tabular}

\section{Application in PON}

Both proposed splitter designs were deployed in a PON and compared to each other in terms of physical reach of the PON, Q-factor and Bit Error Rate (BER). The goal of the simulations was to show the practical benefits of the proposed splitters in the optical access network, which transmits data/voice and video streams in direction to users. The simulation scheme is shown in Fig. 6 .

We focused on the downstream traffic, which does not restrict the generality of the problem. The network consists of three parts: OLT which includes transceivers at the provider's side, ODN (the transmission path components) and ONU, including transceivers at the customer's 

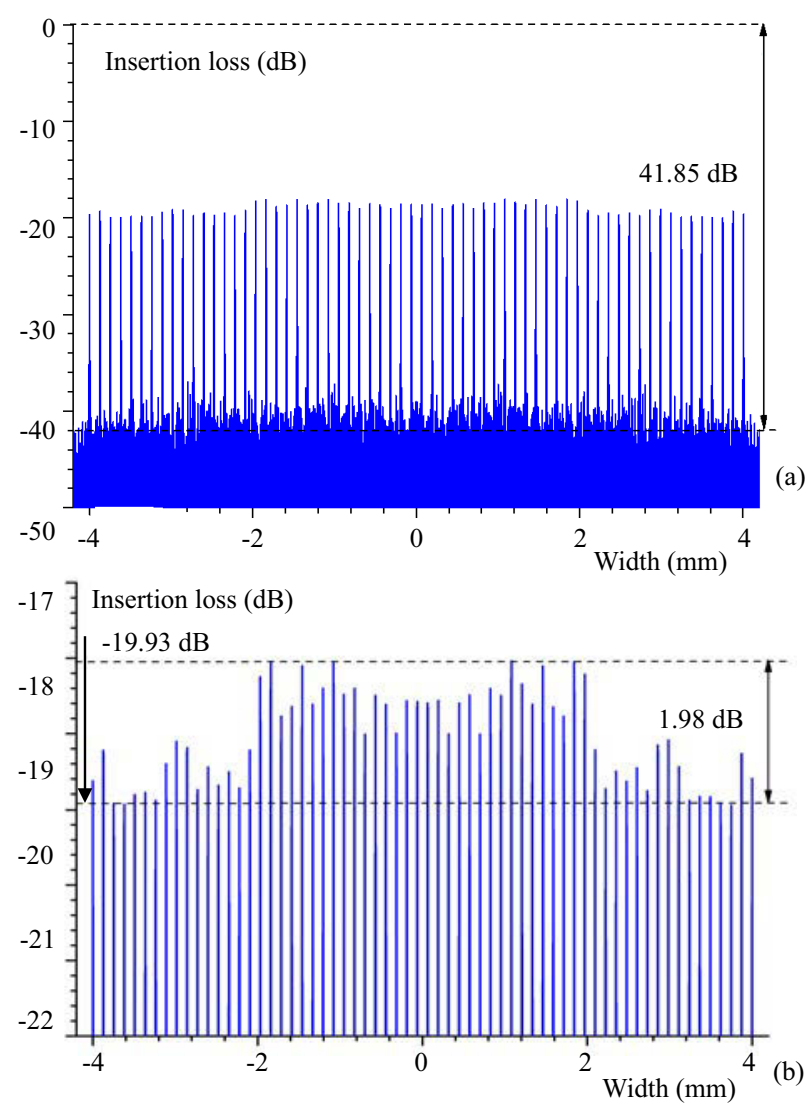

Fig. 5. $1 \times 64$ Y-branch standard splitter, core $5.5 \times 5.5 \mu \mathrm{m}$ : (a) Field distribution at the output of the modeled splitter and the background isolation, $B X=41.85 \mathrm{~dB}$; (b) - Detailed view of the field displaying the non-uniformity, $I L u=1.98 \mathrm{~dB}$ and the insertion loss, $I L=-19.93 \mathrm{~dB}$

premises. We simulated both GPON (2.5 Gbit/s downstream) and XG-PON (10 Gbit/s downstream). Voice transmitter can be considered as a VoIP service due to its current applications and wide deployments globally.

The data and VoIP transmitters generate optical NonReturn-to-Zero modulated signals, multiplexed with the video component using the Coarse WDM technique. Wavelength selection is shown in Fig. 1. The $800 \mathrm{Mbit} / \mathrm{s}$ video stream was generated using a 16-QAM modulation. The data/voice/video transmitter's output power was $-3 \mathrm{dBm}$, which is a commonly used value for optical transmitters.

The ODN consists of a 20-km long standard SMF with the attenuation factor of $0.2 \mathrm{~dB} / \mathrm{km}$ and the 164 splitter to be analyzed. The drop-off cable is several meters long. Its purpose is to consider the fibre connections at the customer promises. We used different components in OptSim environment for signal analysis, such as spectrum analyzers, power meters, among others.

The investigated signal parameters are BER and Qfactor. The threshold BER value is $10^{-12}$, and the limit Q-factor ensuring correct transmission is 7. The Q-factor decreases as the BER increases. Essentially, Q-factor indicates the minimum required optical signal to noise ratio to achieve a certain BER value. It can be calculated as

$$
Q=\frac{\mu_{1}-\mu_{0}}{\sigma_{1}+\sigma_{0}}
$$

where $\mu_{0}, \mu_{1}$ stands for the mean log.0, log.1 level values, and $\sigma_{0}, \sigma_{1}$ for their standard deviations. The mathematical relation between Q-factor and BER [24], [25] can be expressed as

$$
\mathrm{BER}=\frac{1}{2} \operatorname{erfc}\left(\frac{Q}{\sqrt{2}}\right)
$$

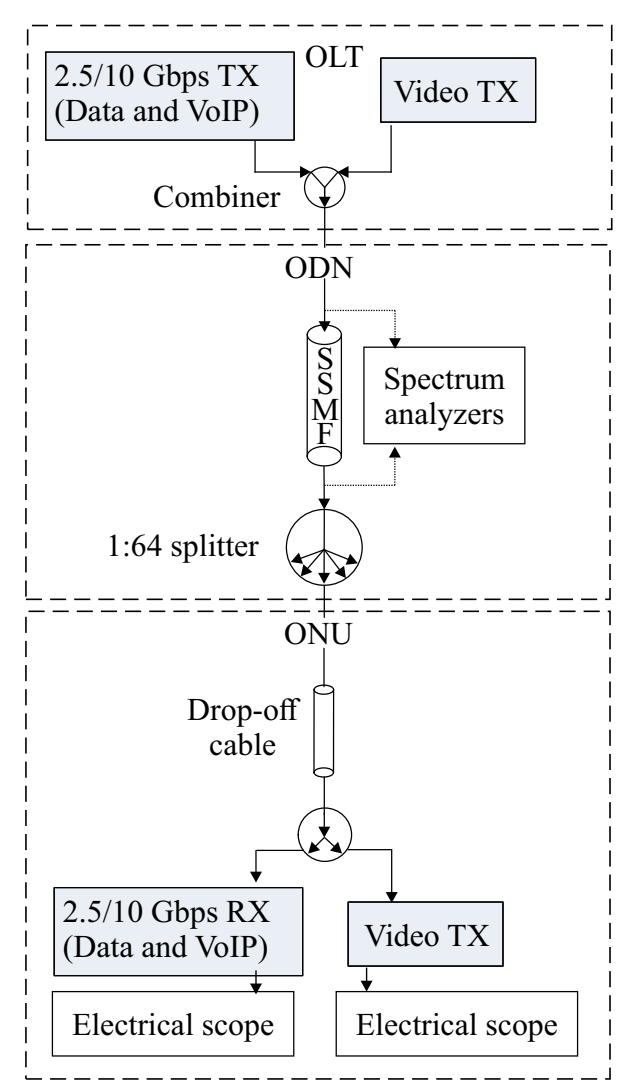

Fig. 6. GPON/XG-PON simulation schemes with triple - play services employing the designed 164 splitters

The fibre propagation equation is solved by the splitstep method, which applies separately optical linear and non-linear effects. There are two main methods which differ on the way how the optical linear effects are calculated: Time domain split step (TDSS) [26] and frequency domain split step (FDSS). The simulations that we have performed in OptSim software environment are based on the TDSS technique. This method uses the convolution product in the discrete time [9], as expressed in

$$
A_{L}[n]=A[n] * h[n]=\sum_{k=-\infty}^{\infty} A[k][n-k]
$$

where $A$ is the optical field intensity, $L$ is the operator related to linear effects [27], such as dispersion [28] and $h$ is the impulse response of $L$. 

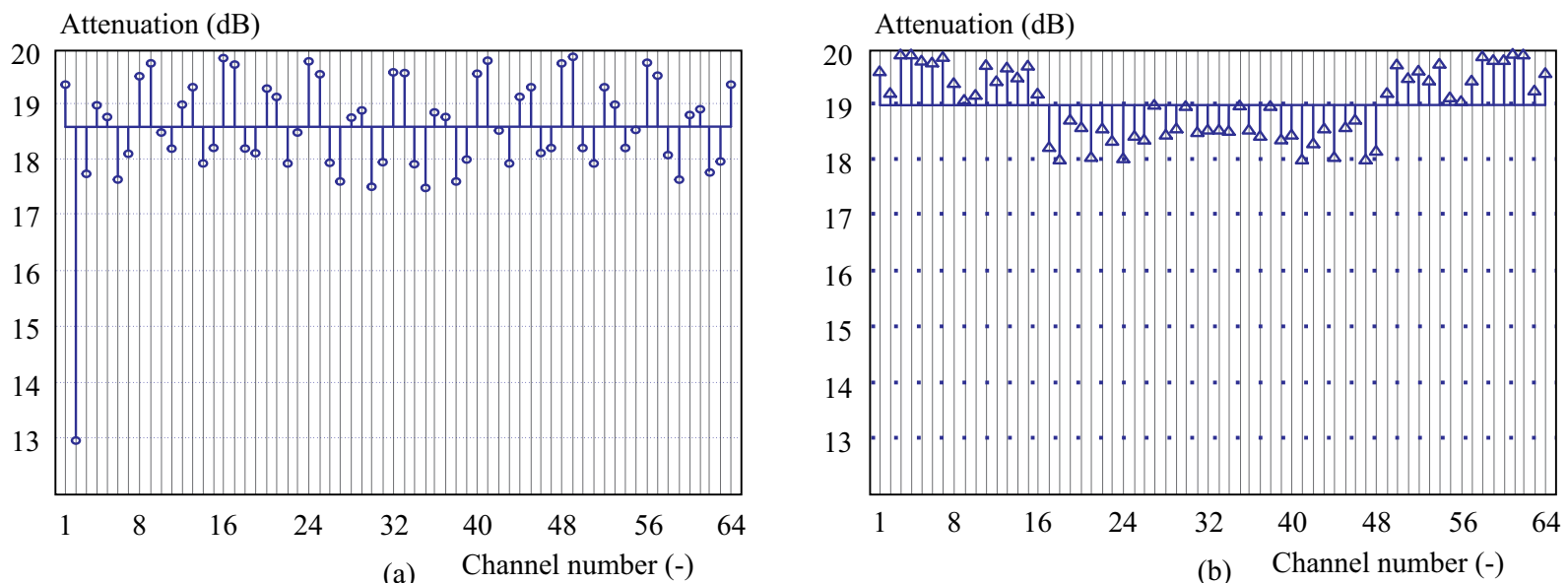

Fig. 7. (a) - Attenuation and deviations from the mean value for each of the output ports for both: standard and (b) - length-optimized (triangles) 164 Y-branch splitters
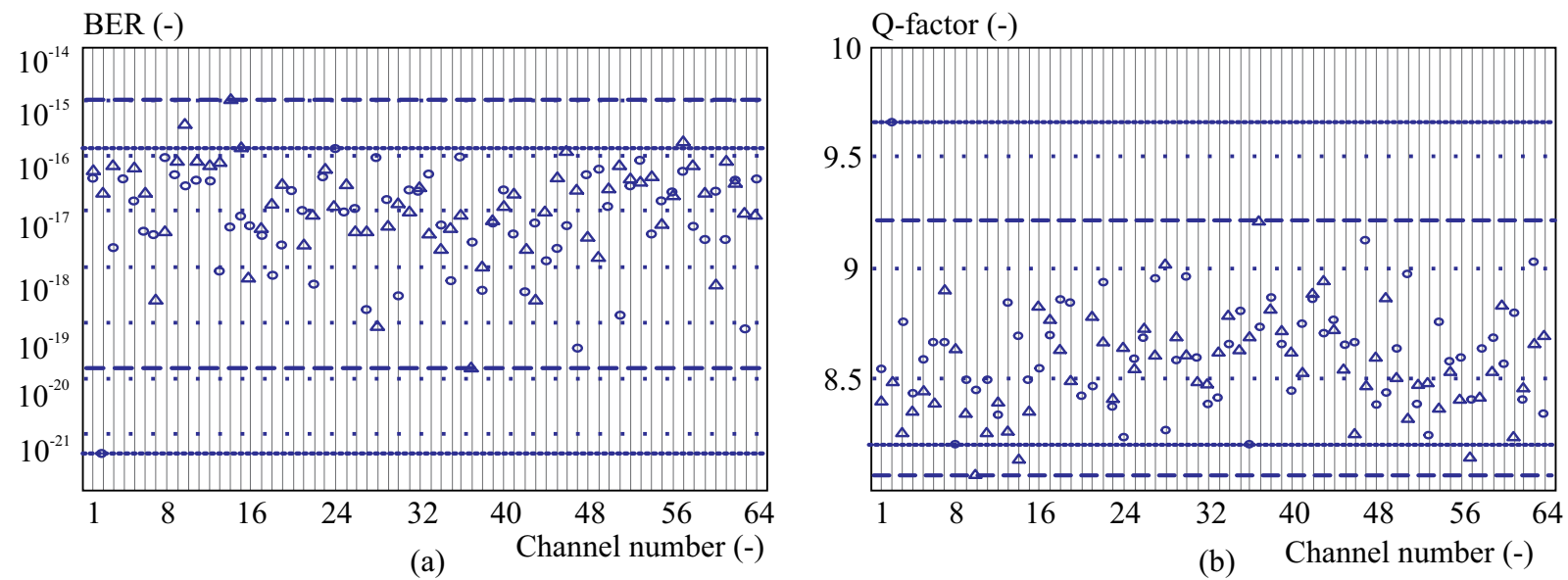

Fig. 8. (a) - BER and (b) - Q-factor values for GPON with triple-play services (circles - standard splitter; triangles - optimized splitter)

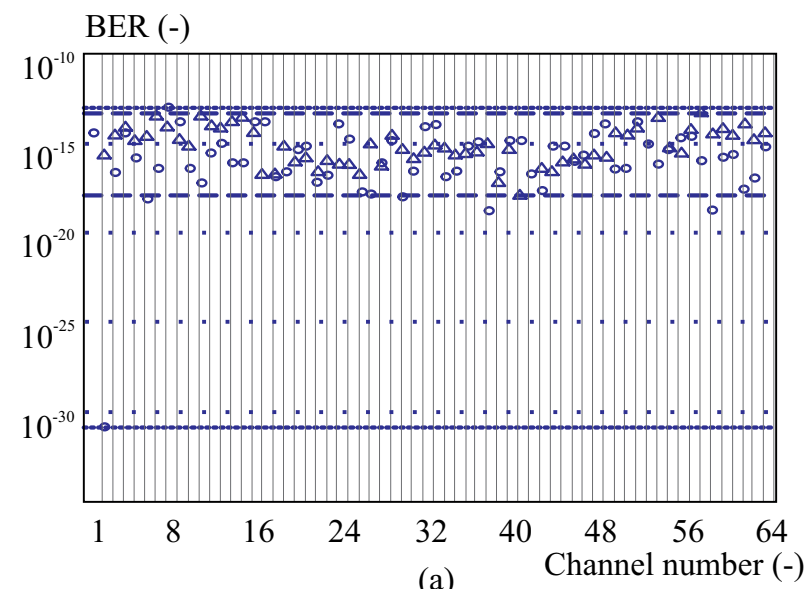

(a)

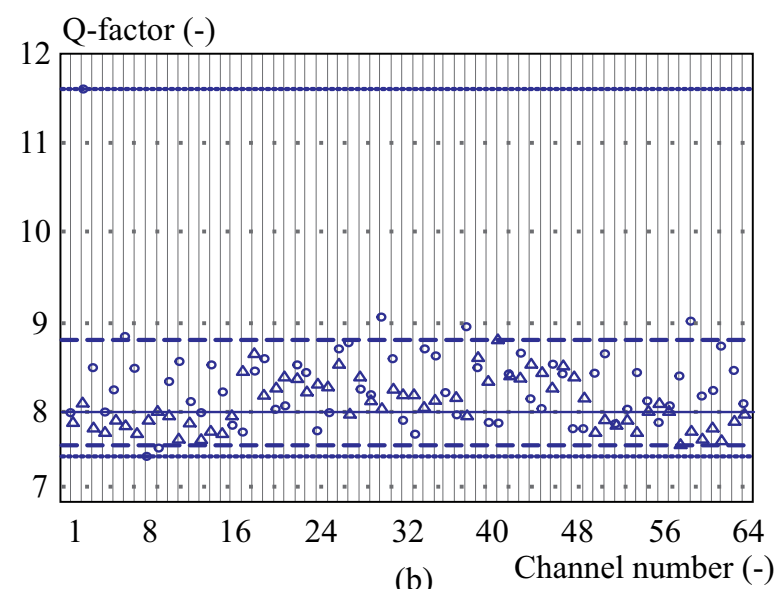

(b)

Fig. 9. (a) - BER and (b) - Q-factor values for XG-PON with triple-play services (circles - standard splitter; triangles - optimized splitter)

The TDSS method has no constrains on the shape of a signal spectrum and it has no modelling limits. On the other hand, FDSS introduces unavoidable intrinsic errors due to the circular convolution, which leads to undesirable aliasing effects and therefore to the possibility of inaccurate simulation results. Unlike the FDSS method,
TDSS method exhibits higher immunity against aliasing errors and exact differential group delays, at the cost of more complex implementation and higher computational requirements [9]. However, TDSS takes advantage of the parallel computing (software pipelining), which significantly improves the TDSS computation speed. 


\section{Discussion}

We compared the main specifications of the standard $6 \mu \mathrm{m} \times 6 \mu \mathrm{m}$ and the length-optimized $5.5 \mu \mathrm{m} \times 5.5 \mu \mathrm{m}$ 164 Y-branch splitters, such as non-uniformity $I L u$, insertion loss $I L$, maximum background noise $B X$ and chip size. From Tab. 4, it is evident that the most significant changes in splitter design are related to the better value of parameter "non-uniformity" ILu, also called insertion loss non-uniformity.

Table 4. Comparison of parameters for standard and low-loss length optimized waveguide core $1 \times 64$ Y-branch splitters

\begin{tabular}{lcc}
\hline & Standard & Optimized \\
& $6 \mu \mathrm{m} \times 6 \mu \mathrm{m}$ & $5.5 \mu \mathrm{m} \times 5.5 \mu \mathrm{m}$ \\
\hline$I L u$ & $2.67 \mathrm{~dB}$ & $1.98 \mathrm{~dB}$ \\
$I L$ & $-19.89 \mathrm{~dB}$ & $-19.93 \mathrm{~dB}$ \\
$B X$ & $-42.24 \mathrm{~dB}$ & $-41.85 \mathrm{~dB}$ \\
Chip size & $318000 \mu \mathrm{m}$ & $120000 \mu \mathrm{m}$ \\
\hline
\end{tabular}

The individual values of the insertion losses per each output port have been calculated, and the results are illustrated in Fig. 7. The scale of $y$ axis in Fig. 7 has been adjusted to distinguish better between particular deviations from the mean attenuation value and to compare both optical splitter designs.

Figure 7 clearly proves that the non-uniformity has been significantly improved when we used the lengthoptimized 164 optical splitter with $5.5 \mu \mathrm{m} \times 5.5 \mu \mathrm{m}$ waveguide core size. This is very beneficial especially for PONs with triple-play services as the provider can offer similar signal quality and therefore it can maintain more efficiently the same service level agreement (SLA) for each of the customers.

Figures 8 and 9 show the results on data/voice components when deploying both splitters in GPON and XGPON scenarios. As the changes didn't concern the video signal, the video service delivery remained the same under acceptable thresholds in both cases; hence it is not taken into account for comparison.

The minimum and maximum reached values of Qfactor and BER are displayed with dashed lines. GPON traffic runs at $2.5 \mathrm{Gbit} / \mathrm{s}$ data/voice stream and the splitting non-uniformity enhancement was just slightly improved, as all the BER values were too low (respectively Q-factor too high) at the receivers.

As a result, small changes in attenuation of splitter's output ports were not noticeably influencing the overall service quality to end users. The minimum and maximum achieved BER values were differing by a factor of $10^{6}$ when the standard splitter was used, and by a factor of $10^{5}$ in case of the optimized splitter.

For the higher speed rates as those in XG-PON and above $10 \mathrm{Gbit} / \mathrm{s}$, the optical signal quality significantly decreases if the other network parameters are not properly tuned.
From Fig. 9 it can be seen that the minimum and maximum obtained BER values in XG-PON scenario differ by a factor of $10^{17}$ in case of the standard splitter deployment and by only $10^{4}$ when the optimized optical splitter is deployed in the network. Therefore, the power split over all output ports becomes a more crucial parameter to maintain similar customer SLAs.

\section{Conclusions}

We proposed a new length-optimized 164 Y-branch optical splitter with a $5.5 \mu \mathrm{m} \times 5.5 \mu \mathrm{m}$ waveguide core size, which suppressed the presence of the first mode and this way it reduced the non-uniformity of the power split compared to standard $6 \mu \mathrm{m} \times 6 \mu \mathrm{m}$ waveguide core size splitter.

It is possible to optimize the signal distribution in access networks using WDM technique. For comparison purposes, we selected GPON and XG-PON with tripleplay services. We showed that the length-optimized splitter with $5.5 \mu \mathrm{m} \times 5.5 \mu \mathrm{m}$ waveguide core achieved better results in terms of BER, Q-factor, especially for high speed rates like $10 \mathrm{Gbit} / \mathrm{s}$ (XG-PON), and they could eventually provide with the improvement of the overall system performance, whereas maintaining the same implementation and operational costs.

\section{Acknowledgements}

This work has been supported by the CTU grant under project SGS16/227/OHK3/3T/13.

\section{REFERENCES}

[1] D. Benedikovic, J. Litvik, M. Kuba, M. Dado and J. Dubovan, "Influence of Nonlinear Effects WDM System with Non-Equidistant Channel Spacing using Different Types of High-Order PSK and QAM Modulation Formats", Proc. SPIE 8429, Optical Modelling and Design II, 2012.

[2] J. Latal, P. Koudelka, P. Siska, J. Vitasek and V. Vasinek, "WDM-PON Network Simulation with Different Implementation of Optical Amplifier the Line", Proc. SPIE 9193, Novel Optical Systems Design and Optimization XVII, 2014.

[3] G. Z. Markovic, "Wavelength Converters Placement Optical Networks using Bee Colony Optimization", Advances Electrical and Computer Engineering, vol. 16, no.1, pp. 3-10, 2016.

[4] F. Perecar, O. Marcinka, L. Bednarek, M. Lucki, A. Liner, L. Hajek, M. Papes, J. Jaros and V. Vasinek, "The Impacts of Ageing Effects Due to Radiation Burden on Optical Fiber Couplers", Proc. SPIE 9586, Photonic Fiber and Crystal Devices: Advances Materials and Innovations Device Applications IX, 2015.

[5] C. Burtscher and D. Seyringer, "Influence of Waveguide Structure on Y-Branch Splitting Ratio", Proc. SPIE 9133, Silicon Photonics and Photonic Integrated Circuits IV, 2014.

[6] "Gigabit-Capable Passive Optical Networks (GPON): General Characteristics", ITU-T Recommendation G.984.1, 2008, https://www.itu.int/rec/T-REC-G.984.1/en.

[7] "IEEE Standard for Information Technology; Telecommunications and information Exchange between System; Local and Metropolitan Area Networks; Specific Requirements. Part 3: Carrier Sense Multiple Access with Collision Detection 
(CSMA/CD) Access Method and Physical Layer Specifications. Amendment: Media Access Control Parameters, Physical Layers, and Management Parameters for Subscriber Access Networks", IEEE Standard 802.3ah, 2004.

[8] "ITU-T Recommendation G.987.1. 10-Gigabit-Capable Passive Optical Networks (XG-PON): General Requirements", 2010, http://www.itu.int/rec/T-REC-G.987.1/en.

[9] "RSOFT Design Group, Software Manuals: OptSim Application Notes and Examples", OptSim User Guide, OptSim Models Reference, 2010.

[10] K. Grobe and J. P. Elbers, "PON Evolution from TDMA to WDM-PON", Optical Fiber Communication/National Fiber Optic Engineers Conference. OFC/NFOEC 2008, pp. 1-7, vol. 24-28, 2008.

[11] E. Wong, "Next-Generation Broadband Access Networks and Technologies", Journal of Lightwave Technology, vol. 30, no. 4, pp. 597-608, 2012.

[12] J. Segarra, V. Sales, V. Polo and J. Prat, "Dimensioning OLT Architectures for UDWDM-PONs Employing Coherent Transceivers", 17th International Conference on Transparent Optical Networks (ICTON), pp. 1-6, 2015.

[13] J. Prat, I. Cano, M. Presi, I. Tomkos, D. Klonidis, G. Vall-llosera, R. Brenot, R. Pous, G. Papastergiou, A. Rafel and E. Ciaramella, "Technologies for Cost-Effective udWDM-PONs", Journal of Lightwave Technology, vol. 34, no. 2, pp. 783-791, 2016.

[14] A. Shahpari, S. Ziaie, J. D. Reis, Z. Vujicic, M. Lima and A. Teixeira, "Impact of Splitter Configuration Strategies on Power Consumption PON", OptoElectronics and Communications Conference Held Jointly with 2013 International Conference on Photonics Switching (OECC/PS), pp. 1-2, 2013, http://ieeexplore.ieee.org/stamp/stamp.jsp?tp=\&arnumber $=$ $6597578 \&$ isnumber $=6597268$.

[15] G. Rentao, L. Xiaoxu, L. Hui and B. Lin, "Evolutional Algorithm Based Cascade Long Reach Passive Optical Networks Planning", China Communications, vol. 10, no. 4, pp. 59-69, 2013.

[16] C. Zukowski, D. B. Payne and M. Ruffini, "Optical Splitters Configuration for Long-Reach Passive Optical Network Deployment", 18th European Conference on Network and Optical Communications (NOC) and 8th Conference on Optical Cabling and Infrastructure (OC\&i), pp. 185-190, 2013.

[17] S. Pal, C. Zukowski, A. Nag, D. B. Payne and M. Ruffini, "Cable Length Minimisation Long-Reach-PON Planning for Sparsely Populated Areas", the International Conference on Optical Network Design and Modeling, pp. 234-239, 2014, http://ieeexplore.ieee.org/stamp/stamp.jsp?tp= \&arnumber $=6855794 \&$ isnumber $=6855750$.

[18] S. K. Raghuwanshi, V. Kumar, D. Chack and S. Kumar, "Propagation Study of Y-Junction Optical Splitter Using BPM", Communication Systems and Network Technologies (CSNT), 2012 International Conference on, Rajkot, pp. 625-629, 2012.

[19] C. Li, X. Li, X. Qiu, Y. And and Xi, "A Novel Planar Waveguide Super-Multiple-Channel Optical Power Splitter", Journal of Lightwave Technology, vol. 33, no. 24, pp. 5019-5024, 2015.

[20] D. Piehler, "Long-Reach and High Split Ratio Passive Optical Networks", AOE 2008: Asia Optical Fiber Communication and Optoelectronic Exposition and Conference, Shanghai, China, 2009.

[21] L. Wang et al, "Design and Fabrication of Novel Symmetric Low-Loss $1 \times 24$ Optical Power Splitter", Journal of Lightwave Technology, vol. 32, no. 18, pp. 3112-3118, 2014.

[22] L. Kohler, "Study of the Optical Properties of Passive Optical Splitters based on MMI and Y-branch Approach", Vorarlberg University of Applied Science, Austria, master thesis, 2012.
[23] C. Burtscher, D. Seyringer, F. Uherek, J. Chovan and A. Kuzma, "Design of Low Loss 164 Y-Branch Splitter Having Symmetric Splitting Ratio and Small Footprint", 10th International Conference on Advanced Semiconductor Devices \& Microsystems (ASDAM), pp. 1-4, 2014.

[24] W. Freude, R. Schmogrow, B. Nebendahl, M. Winter, A. Josten, D. Hillerkuss, S. Koenig, J. Meyer, M. Dreschmann, M. Huebner, C. Koos, J. Becker and J. Leuthold, "Quality Metrics for Optical Signals: Eye Diagram, Q-Factor, OSNR, EVM and BER", 14th International Conference on Transparent Optical Networks (ICTON), pp. 1-4, 2012.

[25] B. Nebendahl, R. Schmogrow, T. Dennis, A. Josten, D. Hillerkuss, S. Koenig, J. Meyer, M. Dreschmann, M. Winter, M. Huebner, W. Freude, C. KOOS and J. Leuthold, "Quality Metrics Optical Modulation Analysis: EVM and its Relation to Q-Factor, OSNR, and BER", Communications and Photonics Conference (ACP), 2012 Asia, Guangzhou, pp. 1-3, 2012, http://ieeexplore.ieee.org/stamp/stamp.jsp?tp=\&arnumber $=$ $6510607 \&$ isnumber $=6510568$.

26] Y. Zhu and D. V. Plant, "Optimal Design of Dispersion Filter for Time-Domain Split-Step Simulation of Pulse Propagation Optical Fiber", Journal of Lightwave Technology, vol. 30, no. 10, pp. 1405-1421, 2012.

[27] X. Liang, S. Kumar and J. Shao, "Mitigation of Fiber Linear and Nonlinear Effects Coherent Optical Communication Systems", 49th Asilomar Conference on Signals, Systems and Computers, Pacific Grove, CA, pp. 1003-1006, 2015.

$28]$ T. Yipsirimetee and P. Kaewplung, "Optimal Dispersion Compensation and Polarization-Mode Dispersion Compensation All-Optical 40 Gbps-Per-Channel-Based WDM WavelengthRouted Optical Fiber Networks", 21st Annual Wireless and Optical Communications Conference (WOCC), Kaohsiung, pp. 158-162, 2012.

Received 9 October 2017

Rajdi Agalliu (MSc) was born in 1989 in Tirana. He received his Master degree from the Czech Technical University in Prague FEE in 2013. He is now completing his PhD studies at the same faculty. His research interests include networking and optical communications.

Catalina Burtscher (MSc) was born in Targoviste, Romania. She received her MSc from the Vorarlberg University of Applied Sciences in 2014. Since 2014 she has been a PhD student at the Czech Technical University in Prague. Her research interests include integrated optic, passive optical components for telecommunication.

Michal Lucki (PhD) was born in 1980 in Starachowice, Poland. He received his MSc degree from the Kielce University of Technology in Poland in 2004, and his PhD from the Czech Technical University in Prague, FEE in 2007, respectively. He works as a lecturer and researcher at this faculty. His research interests include photonics, optical communications, microelectronics, and quantum physics.

Dana Seyringer (Assoc Prof) Dana Seyringer was born in Martin, Slovakia. She received her first $\mathrm{PhD}$ in microelectronics from the Slovak University of Technology in Bratislava in 1996, and her second PhD at the Johannes Kepler University in Linz, Austria, in 1998. She is internationally known for her work on designs of passive optical components. 